\title{
Immediate mechanical thrombectomy with DynaCT evaluation after percutaneous coronary intervention complicated by acute ischemic stroke
}

\author{
Tomasz Tokarek1,2, Dominika Dykla', Tadeusz Popiela³, Bartłomiej Łasocha4, Stanisław Bartuś1, Łukasz Rzeszutko
}

'Department of Cardiology and Cardiovascular Interventions, University Hospital, Kraków, Poland

${ }^{2}$ Department of Intensive Care and Perioperative Medicine, Jagiellonian University Medical College, Kraków, Poland

${ }^{3}$ Chair of Radiology, Jagiellonian University Medical College, Kraków, Poland

${ }^{4}$ Diagnostic Imaging Unit, University Hospital, Kraków, Poland

\author{
Correspondence to: \\ Tomasz Tokarek, MD, PhD \\ Department of Cardiology \\ and Cardiovascular \\ Interventions, \\ University Hospital \\ Jakubowskiego 2 , \\ 30-688 Kraków, Poland \\ phone: +48 124002262 , \\ e-mail: \\ tomek.tokarek@gmail.com \\ Copyright by the Author(s), \\ 2021 \\ Kardiol Pol. 2021: \\ 79 (9): 1038-1039; \\ DOI: 10.33963/KP.a2021.0043 \\ Received: \\ March 11, 2021 \\ Revision accepted: \\ June 202021 \\ Published online: \\ June 22, 2021
}

The incidence of acute ischemic stroke secondary to percutaneous coronary intervention (PCl) ranges from $0.1 \%$ to $0.6 \%$ [1]. Furthermore, strokes related to $\mathrm{PCl}$ happen also as a result of reversible occlusions of large arteries [2]. Various predictors of acute ischemic stroke during $\mathrm{PCl}$ have been established, one of them being the radial access site $[3,4]$. Mechanical thrombectomy is a rapid, safe, and feasible treatment option for acute ischemic stroke and has become the standard of care $[2,5]$. The neurological outcome depends on the time from the onset of symptoms to treatment, and even a few-minute delay can critically influence the outcome. Thus, establishing a diagnosis of acute stroke without the need to transfer the patient from the catheterization laboratory to the computed tomography (CT) facility and later to the interventional radiology department for treatment might significantly shorten the time to reperfusion $[1,2,5]$.

A 64-year-old Caucasian male with a history of prior ST-segment elevation myocardial infarction treated with $\mathrm{PCl}$ in the left anterior descending coronary artery (LAD), arterial hypertension, type 2 diabetes mellitus, and hypercholesterolemia was admitted to our department with a non-ST-segment elevation myocardial infarction. Transthoracic echocardiography showed decreased left ventricular ejection fraction (35\%) with disturbed contractility in several segments. The patient was rushed to the catheterization laboratory where coronary angiography revealed a multivessel disease with critical stenosis in the right coronary artery (RCA) and the diagonal branch (Dg) of the left coronary artery (Figure 1A, B).
A radial access site was established and $\mathrm{PCl}$ of RCA with stent implantation was performed. No periprocedural complications were observed. The patient was planned for delayed coronary intervention in $L A D$ and $D g$, again via radial access. During stent implantation, a neurological deterioration with focal deficits was observed (motor weakness of the left upper limb and motor aphasia). After consultation with the neurologist, the patient underwent immediate DynaCT (angiographic CT) (Siemens, Medical Solutions, Erlangen, Germany) followed by an immediate direct cerebral digital subtraction angiogram (CDSA) via the right femoral artery. Intracranial hemorrhage was ruled out (Supplementary material, Video S1). Thrombotic occlusion of the right vertebral and basilar arteries was confirmed (Figure 1C). Immediate aspiration thrombectomy and stent retriever technique were used to remove the thrombus and restore blood flow. The control angiography confirmed the patency of previously occluded arteries (Figure 1D-F). A control CT one day later excluded further ischemic or hemorrhagic events. The neurological assessment confirmed a good clinical outcome with no focal neurological deficits (2 points on the National Institutes of Health Stroke Scale). Dual antiplatelet therapy was continued.

Our case suggests that immediate direct cerebral digital subtraction angiogram (cDSA) followed by immediate mechanical thrombectomy reduces delay to treatment and might be a safe and feasible treatment option for acute ischemic stroke secondary to $\mathrm{PCl}$. Quick and safe access to this treatment option should be widely provided $[2,5]$. 


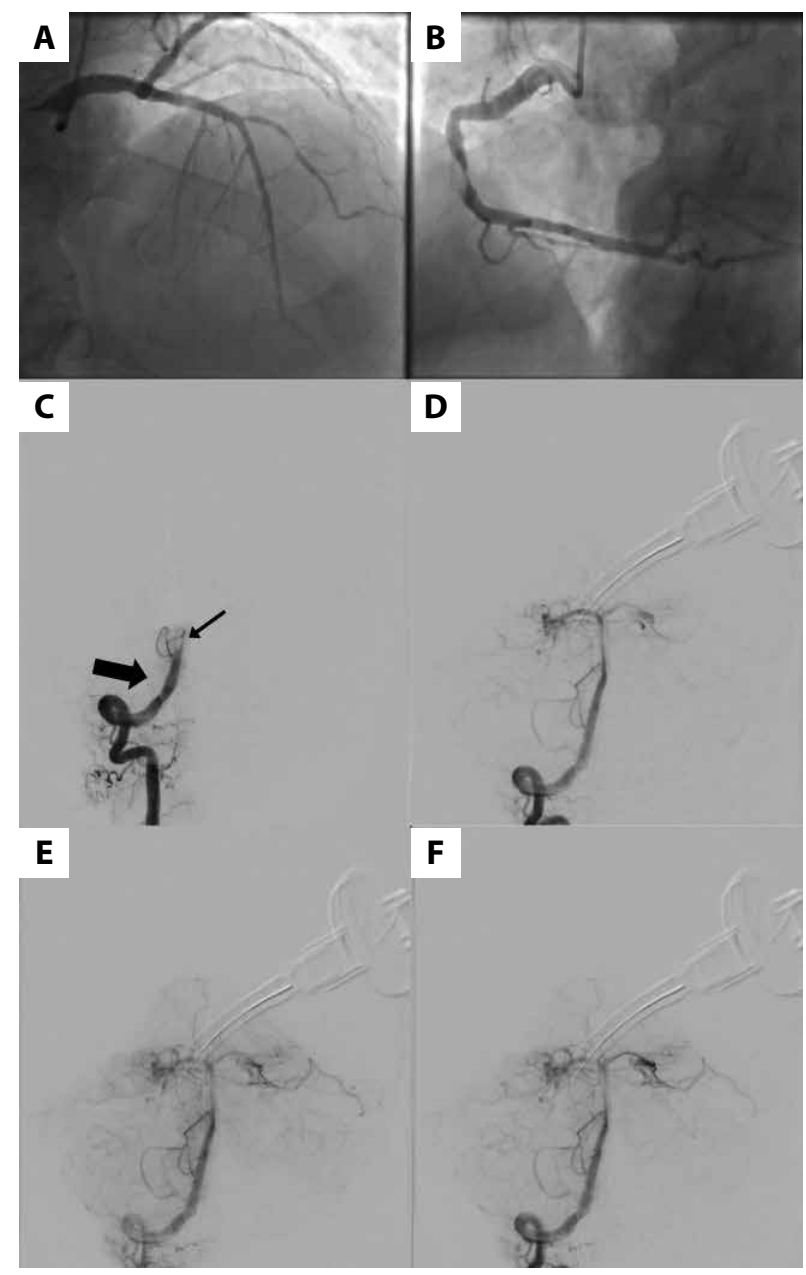

Figure 1. A, B. Coronary angiography and cerebral digital subtraction angiography. C. Thick arrow indicates the right vertebral artery. Thin arrow points at thrombus occlusion of the right vertebral and basilar artery. D-F. The final angiography after mechanical thrombectomy

\section{Supplementary material}

Supplementary material is available at https://journals. viamedica.pl/kardiologia_polska.

\section{Article information}

Conflict of interest: None declared.

Open access: This article is available in open access under Creative Common Attribution-Non-Commercial-No Derivatives 4.0 International (CC BY-NC-ND 4.0) license, allowing to download articles and share them with others as long as they credit the authors and the publisher, but without permission to change them in any way or use them commercially. For commercial use, please contact the journal office at kardiologiapolska@ptkardio.pl.

How to cite: TokarekT, Dykla D, Popiela T, et al. Immediate mechanical thrombectomy with DynaCT evaluation after percutaneous coronary intervention complicated with acute ischemic stroke. Kardiol Pol. 2021; 79(9): 1038-1039, doi: 10.33963/KP.a2021.0043.

\section{REFERENCES}

1. Werner N, Bauer T, Hochadel M, et al. Incidence and clinical impact of stroke complicating percutaneous coronary intervention: results of the Euro heart survey percutaneous coronary interventions registry. Circ Cardiovasc Interv. 2013; 6(4): 362-369, doi: 10.1161/CIRCINTERVENTIONS.112.000170, indexed in Pubmed: 23899872.

2. Hopkins LN. Mechanical thrombectomy for ischemic stroke: a role for cardiology! Kardiol Pol. 2020; 78(7-8): 798-799, doi: 10.33963/KP.15565, indexed in Pubmed: 32844614.

3. Tokarek T, Dziewierz A, Plens K, et al. Radial approach expertise and clinical outcomes of percutanous coronary interventions performed using femoral approach.J Clin Med. 2019;8(9): 1484, doi: 10.3390/jcm8091484, indexed in Pubmed: 31540442.

4. Dziewierz A, Siudak Z, Tokarek T, et al. Determinants of stroke following percutaneous coronary intervention in acute myocardial infarction (from ORPKI Polish National Registry). Int J Cardiol. 2016; 223: 236-238, doi: 10.1016/j.jicard.2016.08.214, indexed in Pubmed: 27544594.

5. Goyal M, Menon BK, van Zwam WH, et al. HERMES collaborators. Endovascular thrombectomy after large-vessel ischaemic stroke: a meta-analysis of individual patient data from five randomised trials. Lancet. 2016; 387(10029): 1723-1731, doi: 10.1016/S0140-6736(16)00163-X, indexed in Pubmed: 26898852. 